\title{
Early Overfeed-Induced Obesity Leads to Brown Adipose Tissue Hypoactivity in Rats
}

\author{
Douglas L. de Almeida Gabriel S. Fabrício Amanda B. Trombini \\ Audrei Pavanello Laize P. Tófolo Tatiane A. da Silva Ribeiro \\ Paulo C. de Freitas Mathias Kesia Palma-Rigo \\ Laboratory of Secretion Cell Biology, Department of Biotechnology, Genetics and Cell Biology, State \\ University of Maringá - Maringá/PR, Brazil
}

\section{Key Words}

Perinatal overfeeding • Thermogenesis • Transdifferentiation

\begin{abstract}
Background/Aims: Brown adipose tissue activation has been considered a potential antiobesity mechanism because it is able to expend energy through thermogenesis. In contrast, white adipose tissue stores energy, contributing to obesity. We investigated whether the early programming of obesity by overfeeding during lactation changes structure of interscapular brown adipose tissue in adulthood and its effects on thermogenesis. Methods: Birth of litters was considered day 0 . On day 2, litter size was adjusted to normal (9 pups) and small (3 pups) litters. On day 21 , the litters were weaned. A temperature transponder was implanted underneath interscapular brown adipose tissue pads of 81-day-old animals; local temperature was measured during light and dark periods between days 87 and 90 . The animals were euthanized, and tissue and blood samples were collected for further analysis. The vagus and retroperitoneal sympathetic nerve activity was recorded. Results: Small litter rats presented significant lower interscapular brown adipose tissue temperature during the light $\left(\mathrm{NL} 37.6^{\circ} \mathrm{C}\right.$ vs. SL $37.2^{\circ} \mathrm{C}$ ) and dark (NL $38^{\circ} \mathrm{C}$ vs. SL $37.6^{\circ} \mathrm{C}$ ) periods compared to controls. Morphology of small litter brown adipose tissue showed fewer lipid droplets in the tissue center and more and larger in the periphery. The activity of vagus nerve was 19,9\% greater in the small litter than in control $(p<0.01)$, and no difference was observed in the sympathetic nerve activity. In adulthood, the small litter rats were $11,7 \%$ heavier than the controls and presented higher glycemia $13,1 \%$, insulinemia $70 \%$ and corticosteronemia 92,6\%. Conclusion: Early overfeeding programming of obesity changes the interscapular brown adipose tissue structure in adulthood, leading to local thermogenesis hypoactivity, which may contribute to obesity in adults.
\end{abstract}




\section{Introduction}

Obesity has been considered a worldwide problem, which has increased in developing countries, including some regions of Africa and Latin America [1]. Obesity is highlighted by its role in the onset and development of several conditions that lead to increased health risk, such as diabetes, cardiovascular diseases and many others [2]. Overfeeding during the postnatal period leads humans and animals to develop obesity, which is maintained in adulthood and is a predictor of future morbidity [3].

Obesity is characterized by fat accumulation resulting from energy imbalance, expressed as a higher intake and lower expenditure of calories [4]. The excess calories are stored as lipids in white adipose tissue (WAT), which is the major form of energy storage. In contrast, brown adipose tissue (BAT) provides an important alternative for energy expenditure because it is rich in mitochondria, which dissipate heat and thus consume large amounts of calories [5]. Heat production in BAT is modulated by the sympathetic nervous system (SNS), which triggers the breakdown of triglycerides from lipid droplets to fatty acids, which are used as an energetic substrate for thermogenesis via the mitochondrial uncoupling protein-1 (UCP1) $[6,7]$.

Brondani et al. characterized energy expenditure in humans as resting metabolic rate, physical activity and adaptive thermogenesis [8]. BAT mitochondria are the main site for adaptive thermogenesis, which responds to diet and changes in temperature. BAT has long been considered a tissue that is predominantly found in human newborns and that disappears a few months after birth. Recent data have demonstrated that BAT is also present and active in adult humans $[9,10]$.

Raising animals in 'small litters' (SL) provides a well-established animal model for studying obesity. Artificial reduction of the natural litter size to few rats (3 or 4) per dam exposes pups to early overfeeding, causing the onset of premature obesity that is maintained throughout life [11]. Rats raised in SL show body weight gain and lower BAT-UCP1 expression in adulthood [12]. Some studies demonstrated that UCP1\% mice became obese with higher fat accumulation $[13,14]$. Other studies, however, indicated that under thermoneutral conditions, the absence of the UCP1 gene does not result in obese mice [15]. The expression or not of the UCP1 gene in ob/ob mice do not affect altered energy expenditure at normal temperature [16]. These studies reflect the controversial role of BAT-UCP1 in weight gain under thermoneutrality.

Interscapular BAT (IBAT) is the main site of thermogenesis in rodents, and changes in the IBAT temperature reflects its activity [17]. Therefore, the aim of this study was to investigate whether the early programming of obesity, induced by overfeeding during the perinatal period, causes changes in the structure and main tissue function of IBAT, thus altering energy expenditure in young adult life.

\section{Materials and Methods}

\section{Animals}

Pregnant Wistar rats were placed in individual cages until the birth of the litters (day zero). On day 2 , the litters were adjusted to 9 pups for the normal litters and to 3 pups for the small litters. Twentyone-day-old pups were weaned with 3 rats per cage, and only male rats from at least 5 different litters were used ( $n=20 \mathrm{NL}, 18 \mathrm{SL})$. During all experimental procedures, the animals had free access to water and standard chow and were kept in climate-controlled room with a controlled photocycle (12h light/12h dark) and temperature $\left(22^{\circ} \mathrm{C} \pm 2^{\circ} \mathrm{C}\right)$. All animal protocols were approved by the Ethics Committee of the State University of Maringa, which complies with Brazilian Federal Law.

After weaning, chow consumption was recorded twice a week. This value was calculated by determining the difference between the amount of food remaining (Df) and the total amount of food that was previously 
placed in the cage (Di) and dividing the difference by the number of days and number of rats percage: [FI $(\mathrm{g})=(\mathrm{Df}-\mathrm{Di}) / 3 / 3]$ [18]. The area under the curve (AUC) for the food consumption versus time was calculated for the entire observation period (21-90 days).

\section{IBAT Temperature}

Eight-one-day-old animals were anesthetized using ketamine and xylazine ( 3 and $0.6 \mathrm{mg} / 100 \mathrm{~g}$ of body weight, respectively),and a temperature transponder (implantable programmable temperature transponder 300 - IPTT-300, BioMedic Data Systems, Seaford, DE) was implanted under the IBAT pads and secured to the surrounding muscle. Before implantation, each transponder was checked comparing the given transponder temperature and ambient temperature measured with a thermometer. The temperature from both pads was measured [19]. Animals were placed in individual cages and had 6 days to recover from surgery. A recording apparatus (DAS 5002 Notebook System; BioMedic Data Systems, Seaford, DE) was used to measure temperature. Measurements were made twice a day between days 87 and 90, around one hour after the lights were turned on or off (8:00 am and 8:00 pm).

\section{Autonomic Nerve Activity}

From each group, a separated set of 90 -day-old rats $(\mathrm{n}=15 \mathrm{NL}, 12 \mathrm{SL})$ with no transponder implantation was anesthetized using thiopental ( $45 \mathrm{mg} / \mathrm{kg}$ of body weight) after $12 \mathrm{~h}$ of fasting. The vagal nerve superior branch and a sympathetic branch nerve from the lumbar plexus (major splanchnic nerve) were surgically exposed and placed on a pair of platinum electrodes. Recordings were made with a Bio-Amplificator (Insight $\circledast$, Ribeirão Preto, Brazil) in the $1-80 \mathrm{kHz}$ range and amplified 10000 -fold, as previously described [20]. The average numbers of spikes $/ 5 \mathrm{~s}$ were used to calculate the nerve firing rate from 5 to 7 sections of 15 s recordings for each rat.

\section{Blood analysis and Tissue collection}

Ninety-one-day-old animals were weighed, anesthetized (thiopental (45 mg / $\mathrm{kg}$ of body weight) and euthanized via quick decapitation. Blood samples were collected and centrifuged, and the plasma was stored at $-20^{\circ} \mathrm{C}$ for subsequent analysis. The glucose concentration was measured using the glucose oxidase method [21] with a commercial kit (Gold Analisa ${ }^{\circledR}$, Minas Gerais,Brazil). The insulin and corticosterone levels were measured using a radioimmunoassay [22]. Insulin variation coefficients was $9.8 \%$, the inferior and superior detection limits was, respectively, $0.006 \mathrm{ng} / \mathrm{ml}$ and $100 \mathrm{ng} / \mathrm{ml}$. Corticosterone variation coefficients was $7.1 \%$, the inferior and superior detection limits was, respectively, $7.7 \mathrm{ng} / \mathrm{ml}$ and $800 \mathrm{ng} /$ $\mathrm{ml}$. Fat from the retroperitoneal, epididymal and IBAT pads was dissected and weighted. An IBAT lobe was placed in $4 \%$ paraformaldehyde, fixed for 24 hours and then embedded in paraffin. Five $\mu \mathrm{m}$ sections for every $30 \mu \mathrm{m}$ interval were made using a microtome and placed on glass slides. The slices were stained with hematoxylin and eosin, and the sections were examined using light microscopy ( 5 optic zones of 40x per sections).

\section{Statistical analysis}

The results are given as the mean \pm SEM; data were analyzed using Student's t-test, except for the IBAT temperature, which was analyzed using two-way ANOVA (factors: litter size and period) followed by Tukey's multiple comparisons test for comparisons between groups. $\mathrm{P}<0.05$ was considered statistically significant. The tests were performed using GraphPad Prism version 5.0 for Windows (GraphPad Software Inc., San Diego, CA, USA).

\section{Results}

The SL animals started to show significantly greater body weight at 4 days of life (NL: $11.5 \mathrm{~g}$ vs SL: $14.7 \mathrm{~g} ; \mathrm{p}<0.001$ ) and at weaning they were $33.6 \%$ heavier than the NL rats ( $\mathrm{p}<0.0001$; Fig. 1). Obesity initiated in perinatal period was maintained in the SL adult rats (NL: $366.1 \mathrm{~g}$ vs SL 409.1g, $\mathrm{p}<0.001$; Table 1). SL showed greater food intake throughout life compared with NL animals, as measured by the AUC from 21- to 90-day-old animals (NL: $679.5 \pm 11.4$ vs SL: $728.4 \pm 15.4, \mathrm{p}<0.05)$. 
Table 1. Food intake between days 21 to 90 and metabolic profile in 91-day-old animals. The values are the mean \pm SEM $(n=20 \mathrm{NL}$ and 18 SL). ${ }^{*} \mathrm{p}<0.05, \quad{ }^{* *} \mathrm{p}<0.01$, $* * * \mathrm{p}<0.001$

\begin{tabular}{lcc}
\hline & NL & SL \\
\hline Food Intake(AUC 21-90 days old) & $679.5 \pm 11.4$ & $728.4 \pm 15.4^{*}$ \\
Body Weight (g) & $366.1 \pm 5.4$ & $409.1 \pm 3.2^{* * *}$ \\
IBAT Fat (g/100g bw) & $0.046 \pm 0.001$ & $0.064 \pm 0.003^{* * *}$ \\
Epididimal Fat (g/100g bw) & $0.90 \pm 0.03$ & $1.07 \pm 0.05^{*}$ \\
Retroperitoneal Fat (g/100g bw) & $1.15 \pm 0.04$ & $1.40 \pm 0.06^{* *}$ \\
Fasting Glycemia (mg/dL) & $111.4 \pm 4.5$ & $126.0 \pm 2.1 *$ \\
Fasting Insulinemia (ng/mL) & $0.10 \pm 0.01$ & $0.17 \pm 0.02 *$ \\
Corticosterone (ng/mL) & $338.8 \pm 83.6$ & $652.7 \pm 24.9^{* *}$ \\
\hline Values are Mean \pm SEM. ${ }^{*}$ P value $<0.05 ; * *$ P value $<0.01 ; * * * P$ value $<0.001$
\end{tabular}

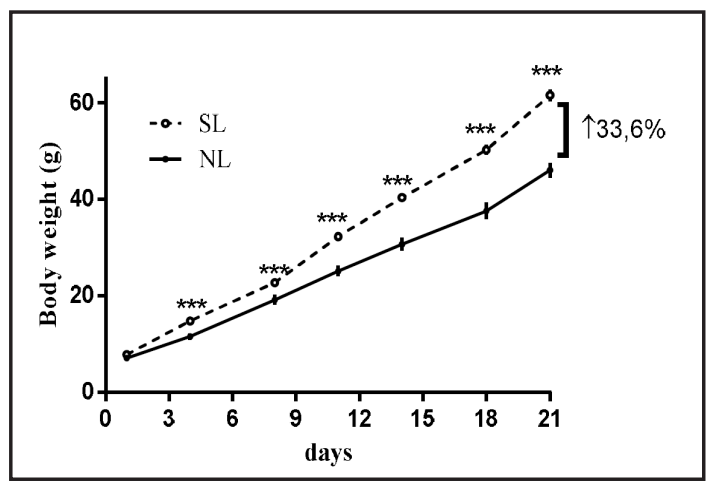

Fig. 1. Weight gain curve for 0 - to 21-day-old animals. Number of litters: NL=5; $S L=6$. ${ }^{* * *} \mathrm{p}<0.001$.

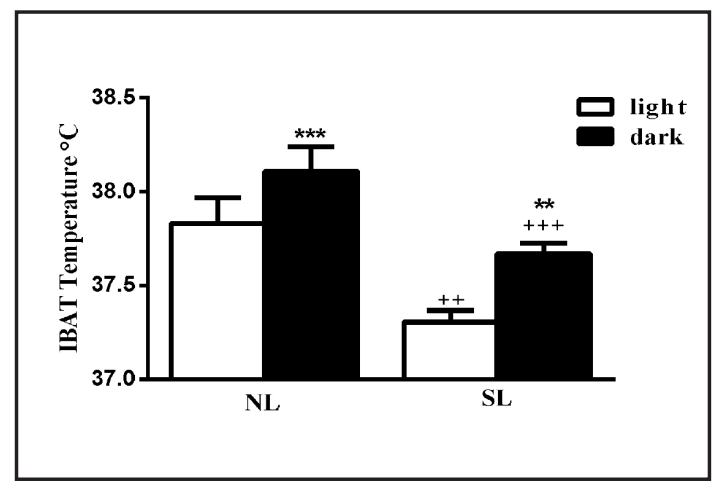

Fig. 2. IBAT temperature between days 87 and 90 ( $\mathrm{n}=20 \mathrm{NL}$ and $18 \mathrm{SL}$ ). ${ }^{* *} \mathrm{p}<0.01$; $^{* * *} \mathrm{p}<0.001$, statistical significance of light versus dark periods. $++p<0.01 ;+++p<0.001$, statistical significance of the differences between NL and SL.

Both groups showed higher IBAT temperature during the dark (active) period than during the light period ( $\mathrm{p}<0.001$ ) (Fig. 2). Lower IBAT temperature was observed in SL animals than in $\mathrm{NL}$ in both the light and dark periods (NL $37.6^{\circ} \mathrm{C}$ vs. SL $37.2^{\circ} \mathrm{C}$; NL $38^{\circ} \mathrm{C}$ vs. SL $37.6^{\circ} \mathrm{C}, \mathrm{p}<0.001$, respectively). No interaction was found for litter size vs. period ( $\left.\mathrm{p}=0.66\right)$.

The IBAT of SL rats was $29 \%$ heavier than that of the NL animals $(\mathrm{p}<0.0001$; Table 1$)$. Morphological analysis (Fig. 3) showed a lower number of lipid droplets in the central and peripheral area of the IBAT from SL compared with NL rats (counts per section: central - NL $693.7 \pm 95.3$ vs SL $63.3 \pm 27.4$, p $<0.05$; peripheral - NL $652.6 \pm 69.9$ vs SL $54.4 \pm 12.8, p<0.05$ ). The evaluation of lipid droplets size in the tissue periphery showed greater deposition of hypertrophic lipid droplets (52\%) in IBAT from SL rats compared with NL (9\%).

The vagus nerve activity of the SL rats was $20 \%$ greater than that of the NL animals $(p<0.01)$, while no significant changes were observed in the sympathetic nerve activity (Fig. 4). The SL animals showed higher fat accumulation. The IBAT, retroperitoneal and epididymal fat were heavier in SL than in NL group $(39.1 \%, p<0.001 ; 21.7 \%, p<0.01 ; 18.8 \%$, $\mathrm{p}<0.05$, respectively). The SL animals also showed higher fasting glycemia $(13 \%, \mathrm{p}<0.05)$, insulinemia $(70 \%, \mathrm{p}<0.05)$ and corticosteronemia $(92 \%, \mathrm{p}<0.01)$ (Table 1). 


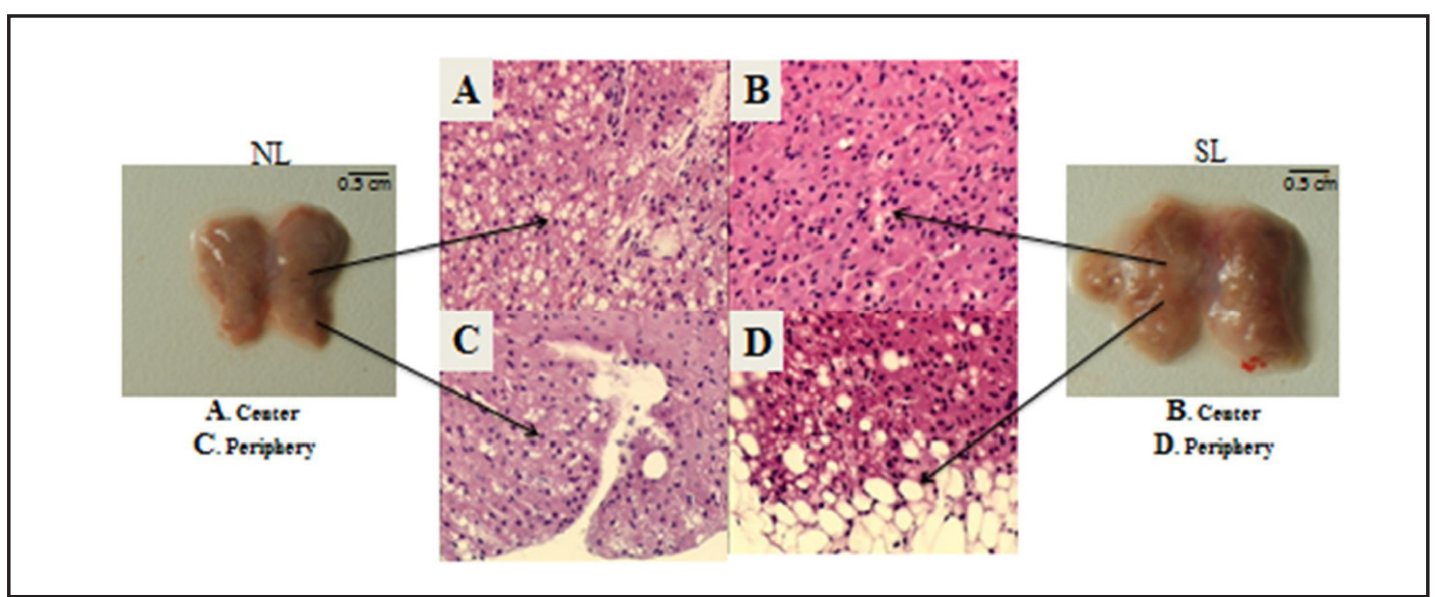

Fig. 3. Representative photo of IBAT morphology and histology ( $n=20 \mathrm{NL}$ and $18 \mathrm{SL}$ ). A Center of the IBAT lobe in NL; B Center of the IBAT lobe in SL; C Periphery of the IBAT lobe NL; D Periphery of the IBAT lobe in SL. Staining: Hematoxylin and Eosin.

Fig. 4. Autonomic nerve activity ( $\mathrm{n}=15 \mathrm{NL}$ and 12 SL). A) Vagal nerve superior branch; B) Retroperitoneal sympathetic nerve. ${ }^{* *} \mathrm{p}<0.01$.

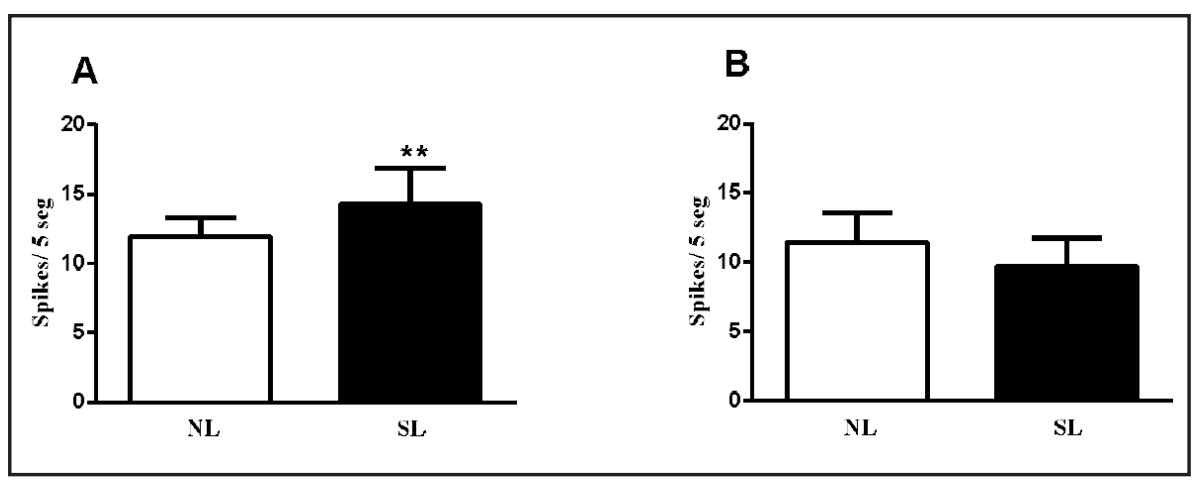

\section{Discussion and Conclusions}

The present study shows that perinatal obesity induces changes in the IBAT architecture of adult SL rats, which may lead to the thermo-hypoactivity observed during light and dark periods. The reduced IBAT temperature observed in SL rats contrasts with the bigger and heavier tissue that also showed changes in lipid droplets composition, which became more similar to WAT.

The artificial reduction in the litter size during the perinatal period was able to promote characteristics of metabolic disorders. The weight gain from childhood was maintained in adulthood and was coupled with other overweight consequences, such as higher fat accumulation and fasting hyperglycemia and hyperinsulinemia, consistent with the literature [11, 23].

The rodent IBAT temperature under thermoneutral conditions shows circadian variation with abrupt changes when the light turns on or off $[24,25]$. Similarly to the NL animals, the SL rats in the present study showed day and night temperature variations, but these animals had lower IBAT temperatures in both periods. Glavas et al. showed that approximately forty-day-old SL mice have a slight reduction in IBAT temperature only during the dark active period [26]. This difference from the present work may depend on species because we used rats instead of mice. Furthermore, older animals (approximately 90-day-old) were evaluated in the present study; thus our findings may demonstrate stronger consequences of programming. The significantly lower temperature in SL animals 
during both periods may indicate that adult rats that were induced to early obesity have a permanently lower metabolic rate. Studies show a close link between IBAT and the body metabolic rate, where increases in IBAT metabolic thermogenesis can lead to a higher whole body metabolic rate [24]. The brain may modulate these changes, and a centrally controlled increase in body temperature of approximately $1^{\circ} \mathrm{C}$ would correspond to an approximately $10 \%$ increase in metabolic rate [27].

Autonomic nervous system imbalance is common in obesity, which favors energy accumulation [28]. The vagus nerve innervates most tissues involved in nutrient metabolism [29]. The present study shows higher parasympathetic activity, as evaluated in the SL vagus nerve. This profile is well recognized in obesity and may modulate hyper insulin secretion $[30,31]$. Furthermore, a vagotomy reduced obesity, ameliorated glucose metabolism and reduced the IBAT weight in a model of hypothalamic obesity [32,33]. This result is consistent with the heavier IBAT observed in SL rats and may suggest that the vagus nerve contributes to IBAT modulation although it does not directly innervate the tissue.

Early studies have proposed that sympathetic nerve activity is reduced in obesity models [34, 35], nevertheless recent studies have questioned this view suggesting that sympathetic changes in obesity are tissue specific and not uniform [36, 37]. Furthermore, the sympathetic splanchnic nerve stimulation has been suggested as a potential treatment for obesity because it reduces food intake and increases metabolic rate [38, 39]. The present study, however, did not show changes in the sympathetic splanchnic nerve activity of SL rats, which may suggest that this nerve has little implication on sympathetic changes observed during obesity. Additionally, studies have shown that only the SNS innervates IBAT and suggest a genuine involvement of SNS-mediated BAT thermogenesis in response to changes in body temperature or nutrient availability $[6,40]$. Previous studies, under thermoneutral conditions, did not show differences in IBAT sympathetic nerve activity over time in lean or obese rats [41]. The absence of sympathetic changes on baseline activity of splanchnic nerve (observed in the present study) and IBAT nerve (showed on literature) suggest that these nerves are not affected in obese animals under thermoneutrality. Although, it is important to highlight that the SNS has tissue-specific actions, and IBAT and the major splanchnic nerve do not appear to respond in the same way to some stimuli [19].

A recent study showed that BAT from obese humans does not respond to ephedrine in the same manner as BAT from lean subjects, which showed greater BAT activity [20]. Animals studies also reported that the sympathetic IBAT activation in response to central insulin administration or hypothermia is attenuated in obese animals [41,42]. Cold exposure induces BAT activation; however, overweight or obese subjects showed less or nonexistent BAT activity in this condition [43]. These studies raise the possibility that BAT is inactive or less effective in obesity. The present study is consistent with this possibility because an attenuated IBAT temperature was observed in both the active and inactive periods.

Increased BAT activity has been considered as an alternative to reduce obesity and fighting metabolic syndrome [44]. Bartelt et al. hypothesized that greater BAT mass could be a factor that promotes triglyceride clearance and weight loss, making BAT mass a target for treating obesity and type 2 diabetes [45]. The IBAT from SL was bigger and heavier than that in the control animals; however, this change was not beneficial for the obese rats. Even with a smaller IBAT control animals produced more heat and consequently expended more energy. The present results suggest that a simple increase in BAT mass is not a treatment by itself because the SL rats had large BAT mass and were still obese, hyperglycemic and hyperinsulinemic. Actually, the SL rats showed impaired glycemic control combined with IBAT hypoactivity. Thus, it is necessary to find alternative methods to increase BAT mass and improve its activity to combat obesity and metabolic syndrome.

Animals with programmed obesity also showed high levels of corticosteronemia, which could indicate changes in the hypothalamic-pituitary-adrenal (HPA) axis, as observed previously in genetic [46] and experimental [47] obesity models. The HPA axis is known for its implication on energy expenditure [48]. Hypercorticosteronemia is likely involved in the metabolic programming of SL rats and may modulate the reduction in BAT metabolism 
along with other effects [49]. Furthermore, rats exposed to overfeed during lactation have showed thyroid dysfunction trough life, with higher plasma TSH, at weaning and hypothyroidism in adult life [23]. Thyroid hormones has a known role in BAT, specially triiodothyronine (T3) which acts promoting thermogenesis and its local activity is mediated by type 2 iodothyronine deiodinase (Dio2) that converts intracellular thyroxine (T4) to T3 [50]. Studies show that hypercorticosteronemia appears to negatively regulate Dio2 activity in peripheral tissues, including BAT [51,52]. Thus, the hypercorticosteronemia observed in SL rats may lead to a reduction in Dio2 and T3, contributing to IBAT hypoactivity.

BAT stores triglycerides in multiple small lipid droplets throughout the tissue; thus, the lipid droplets can be mobilized rapidly in response to adrenergic activation [53]. Histological analysis showed a different morphology in SL rats, where the lipid droplet number was reduced in the center of IBAT and increased in the periphery, where it is also larger. This increased fat storage in the hypertrophic adipocytes may contribute to the IBAT weight gain, enlargement and hypoactivity, indicating to a plasticity of this tissue that may be transformed into WAT [54]. Cinti suggested that brown adipocytes in obese animals gradually change to cells similar in morphology to white adipocytes, including the transformation of the lipid depot from multilocular into unilocular [55]. The hypertrophic lipid droplets from SLIBAT are similar to obesity related-WAT adipocytes that show increasing fat accumulation [53]. Enlarged and pale BAT containing larger cells with unilocular triglyceride depots was observed in $\beta$-less mice housed at $22^{\circ} \mathrm{C}$ [56], suggesting that $\beta$-adrenergic receptors are involved in these changes.

The adipose tissue plasticity is reflected in the changes between BAT and WAT morphological and functional characteristics. Cinti (2002) proposed the transdifferentiation theory, which hypothesize that reversible physiological transdifferentiation in adipose tissue depends on several stimuli, such as obesity (leading to a positive energy balance with increased storage capacity), which modulate the susceptibility to metabolic diseases [55, 57]. The present study showed a structural and functional remodeling of the IBAT. Additionally, Xiao et al. showed that SL rats have reduced thermogenic response to cold stress evidenced by the absent reduction on lipid droplets after $6 \mathrm{~h}$ could stress [12]. Furthermore these animals have lower basal and cold-induced UCP1 mRNA expression [12]. Together, these changes may suggest that IBAT from SL animals are suffering a transdifferentiation to adapt to the obese conditions $[57,58]$.

Obese SL rats presented larger food intake, which contributes to a positive energy balance and fat accumulation. Therefore, these animals have an increased need to store energy, favoring transdifferentiation of IBAT to WAT, which may lead to lower heat production. Consequently, SL animals have an impaired energy homeostasis, given the important role of BAT in energy balance regulation [59], which may be modulated by the brain [24]. It is important to consider that increased fat deposition observed in obesity may contribute to a better thermoregulation leading to less heat from BAT. Although, recent studies from Blessing and collaborators have shown that, under thermoneutrality, BAT has a basic restactive cycle (BRAC), which are not preceded by falls in body or brain temperature, so they may not be homeostatic thermoregulatory responses and may contributes to the body and brain temperature rises, as well as, eating behavior observed in BRAC [60]. Interestingly, obese Zucker rats showed reduced BAT and body temperature compared to lean control animals [61], which accords with the present study. Furthermore, Kontos et al showed that obese rats have longer duration of individual meals and consumed more food over 24 hours, which accords with the present study and may reinforce the view that the obese animals have alteration of the energy expenditure function of the BAT [61].

The obesity programmed by overfeeding in early life induces morphological and functional changes according to a transdifferentiation of IBAT in adulthood. These changes may lead to characteristics similar to WAT and less heat production in obese animals. These changes may contribute to the maintenance of obesity by thermogenesis hypoactivity, which reduces energy expenditure. 


\section{References}

1 W.H.O. World Health Organization, World Health Statistics. 2012.

2 Balducci S, Zanuso S, Nicolucci A, Fernando F, Cavallo S, Cardelli P, Fallucca S, Alessi E, Letizia C, Jimenez A, Fallucca F, Pugliese G: Anti-inflammatory effect of exercise training in subjects with type 2 diabetes and the metabolic syndrome is dependent on exercise modalities and independent of weight loss. Nutr Metab Cardiovasc Dis 2010;20:608-617.

- Jansen PW, Roza SJ, Jaddoe VW, Mackenbach JD, Raat H, Hofman A, Verhulst FC, Tiemeier H: Children's eating behavior, feeding practices of parents and weight problems in early childhood: Results from the population-based generation r study. Int J Behav Nutr Phys Act 2012;9:130.

- 4 Pereira-Lancha LO, Campos-Ferraz PL, Lancha AH Jr: Obesity: Considerations about etiology, metabolism, and the use of experimental models. Diabetes Metab Syndr Obes 2012;5:75-87.

-5 Seale P, Conroe HM, Estall J, Kajimura S, Frontini A, Ishibashi J, Cohen P, Cinti S, Spiegelman BM: Prdm16 determines the thermogenic program of subcutaneous white adipose tissue in mice. J Clin Invest 2011;121:96-105.

6 Richard D, Monge-Roffarello B, Chechi K, Labbe SM, Turcotte EE: Control and physiological determinants of sympathetically mediated brown adipose tissue thermogenesis. Front Endocrinol (Lausanne) 2012;3:36.

7 Cannon B, Houstek J, Nedergaard J: Brown adipose tissue. More than an effector of thermogenesis? Ann N Y Acad Sci 1998;856:171-187.

8 Brondani Lde A, Assmann TS, Duarte GC, Gross JL, Canani LH, Crispim D: The role of the uncoupling protein 1 (ucp1) on the development of obesity and type 2 diabetes mellitus. Arq Bras Endocrinol Metabol 2012;56:215-225.

9 Mattson MP: Perspective: Does brown fat protect against diseases of aging? Ageing Res Rev 2010;9:69-76.

10 Nedergaard J, Bengtsson T, Cannon B: Unexpected evidence for active brown adipose tissue in adult humans. Am J Physiol Endocrinol Metab 2007;293:E444-452.

-11 Plagemann A, Harder T, Brunn M, Harder A, Roepke K, Wittrock-Staar M, Ziska T, Schellong K, Rodekamp E, Melchior K, Dudenhausen JW: Hypothalamic proopiomelanocortin promoter methylation becomes altered by early overfeeding: An epigenetic model of obesity and the metabolic syndrome. J Physiol 2009;587:4963-4976.

12 Xiao XQ, Williams SM, Grayson BE, Glavas MM, Cowley MA, Smith MS, Grove KL: Excess weight gain during the early postnatal period is associated with permanent reprogramming of brown adipose tissue adaptive thermogenesis. Endocrinology 2007;148:4150-4159.

13 Feldmann HM, Golozoubova V, Cannon B, Nedergaard J: Ucp1 ablation induces obesity and abolishes diet-induced thermogenesis in mice exempt from thermal stress by living at thermoneutrality. Cell Metab 2009;9:203-209.

14 Kozak LP, Anunciado-Koza R: Ucp1: Its involvement and utility in obesity. Int J Obes (Lond) 2008;32:S3238.

15 Enerback S, Jacobsson A, Simpson EM, Guerra C, Yamashita H, Harper ME, Kozak LP: Mice lacking mitochondrial uncoupling protein are cold-sensitive but not obese. Nature 1997;387:90-94.

16 Ukropec J, Anunciado RV, Ravussin Y, Kozak LP: Leptin is required for uncoupling protein-1-independent thermogenesis during cold stress. Endocrinology 2006;147:2468-2480.

17 Billes SK, Cowley MA: Catecholamine reuptake inhibition causes weight loss by increasing locomotor activity and thermogenesis. Neuropsychopharmacology 2008;33:1287-1297.

18 de Oliveira JC, Scomparin DX, Andreazzi AE, Branco RC, Martins AG, Gravena C, Grassiolli S, Rinaldi W, Barbosa FB, Mathias PC: Metabolic imprinting by maternal protein malnourishment impairs vagal activity in adult rats. J Neuroendocrinol 2011;23:148-157.

19 Brito MN, Brito NA, Baro DJ, Song CK, Bartness TJ: Differential activation of the sympathetic innervation of adipose tissues by melanocortin receptor stimulation. Endocrinology 2007;148:5339-5347.

-20 Scomparin DX, Gomes RM, Grassiolli S, Rinaldi W, Martins AG, de Oliveira JC, Gravena C, de Freitas Mathias PC: Autonomic activity and glycemic homeostasis are maintained by precocious and low intensity training exercises in msg-programmed obese mice. Endocrine 2009;36:510-517.

21 Trinder P: Determination of blood glucose using an oxidase-peroxidase system with a non-carcinogenic chromogen. J Clin Pathol 1969;22:158-161. 
22 Hermans MP, Schmeer W, Henquin JC: Modulation of the effect of acetylcholine on insulin release by the membrane potential of b cells. Endocrinology 1987;120:1765-1773.

23 Rodrigues AL, de Moura EG, Passos MC, Dutra SC, Lisboa PC: Postnatal early overnutrition changes the leptin signalling pathway in the hypothalamic-pituitary-thyroid axis of young and adult rats. J Physiol 2009;587:2647-2661.

24 Ootsuka Y, de Menezes RC, Zaretsky DV, Alimoradian A, Hunt J, Stefanidis A, Oldfield BJ, Blessing WW: Brown adipose tissue thermogenesis heats brain and body as part of the brain-coordinated ultradian basic rest-activity cycle. Neuroscience 2009;164:849-861.

25 Verty AN, Allen AM, Oldfield BJ: The endogenous actions of hypothalamic peptides on brown adipose tissue thermogenesis in the rat. Endocrinology 2010;151:4236-4246.

26 Glavas MM, Kirigiti MA, Xiao XQ, Enriori PJ, Fisher SK, Evans AE, Grayson BE, Cowley MA, Smith MS, Grove KL: Early overnutrition results in early-onset arcuate leptin resistance and increased sensitivity to high-fat diet. Endocrinology 2010;151:1598-1610.

27 Cannon B, Nedergaard J: Thyroid hormones: Igniting brown fat via the brain. Nat Med 2010;16:965-967.

28 Vinik AI, Maser RE, Ziegler D: Autonomic imbalance: Prophet of doom or scope for hope? Diabet Med 2011;28:643-651.

29 Balbo SL, Mathias PC, Bonfleur ML, Alves HF, Siroti FJ, Monteiro OG, Ribeiro FB, Souza AC: Vagotomy reduces obesity in msg-treated rats. Res Commun Mol Pathol Pharmacol 2000;108:291-296.

- 30 Yoneshiro T, Aita S, Matsushita M, Okamatsu-Ogura Y, Kameya T, Kawai Y, Miyagawa M, Tsujisaki M, Saito M: Age-related decrease in cold-activated brown adipose tissue and accumulation of body fat in healthy humans. Obesity 2011;19:1755-1760.

31 Carey AL, Formosa MF, Van Every B, Bertovic D, Eikelis N, Lambert GW, Kalff V, Duffy SJ, Cherk MH, Kingwell BA: Ephedrine activates brown adipose tissue in lean but not obese humans. Diabetologia 2013;56:147-155.

-32 Inoue S, Nagase H, Satoh S, Saito M, Egawa M, Tanaka K, Takamura Y: Role of the efferent and afferent vagus nerve in the development of ventromedial hypothalamic (vmh) obesity. Brain Res Bull 1991;27:511-515.

-33 Morgan DA, Rahmouni K: Differential effects of insulin on sympathetic nerve activity in agouti obese mice. J Hypertens 2010;28:1913-1919.

34 Bray GA, Inoue S, Nishizawa Y: Hypothalamic obesity. The autonomic hypothesis and the lateral hypothalamus. Diabetologia 1981;20 Suppl:366-377.

-35 Levin BE, Triscari J, Sullivan AC: Altered sympathetic activity during development of diet-induced obesity in rat. Am J Physiol 1983;244:R347-355.

-36 Lambert EA, Straznicky NE, Lambert GW: A sympathetic view of human obesity. Clin Auton Res 2013;23:914.

-37 Lambert GW, Straznicky NE, Lambert EA, Dixon JB, Schlaich MP: Sympathetic nervous activation in obesity and the metabolic syndrome--causes, consequences and therapeutic implications. Pharmacol Ther 2010;126:159-172.

-38 Zheng J, Sonnier T, Vase A, Korivi N, Ajmera P, Morrison SF, DiLorenzo DJ, Greenway FL: A less invasive surgical approach for splanchnic nerve stimulation to treat obesity. Obes Surg 2012;22:1783-1784.

- 39 Zheng J, DiLorenzo DJ, McLaughlin L, Roberts AT, Greenway FL: Stimulation of sympathetic innervation in the upper gastrointestinal tract as a treatment for obesity. Med Hypotheses 2009;72:706-710.

40 Schulz TJ, Tseng YH: Systemic control of brown fat thermogenesis: Integration of peripheral and central signals. Ann N Y Acad Sci 2013;1302:35-41.

41 Hausberg M, Morgan DA, Mitchell JL, Sivitz WI, Mark AL, Haynes WG: Leptin potentiates thermogenic sympathetic responses to hypothermia: A receptor-mediated effect. Diabetes 2002;51:2434-2440.

42 Teff KL: Visceral nerves: Vagal and sympathetic innervation. JPEN J Parenter Enteral Nutr 2008;32:569571.

43 van Marken Lichtenbelt WD, Vanhommerig JW, Smulders NM, Drossaerts JM, Kemerink GJ, Bouvy ND, Schrauwen P, Teule GJ: Cold-activated brown adipose tissue in healthy men. N Engl J Med 2009;360:15001508.

44 Nedergaard J, Bengtsson T, Cannon B: New powers of brown fat: Fighting the metabolic syndrome. Cell Metab 2011;13:238-240.

45 Bartelt A, Merkel M, Heeren J: A new, powerful player in lipoprotein metabolism: Brown adipose tissue. J Mol Med 2012;90:887-893. 
46 Duclos M, Timofeeva E, Michel C, Richard D: Corticosterone-dependent metabolic and neuroendocrine abnormalities in obese zucker rats in relation to feeding. Am J Physiol Endocrinol Metab 2005;288:E254266.

47 Shin AC, MohanKumar SM, Sirivelu MP, Claycombe KJ, Haywood JR, Fink GD, MohanKumar PS: Chronic exposure to a high-fat diet affects stress axis function differentially in diet-induced obese and diet-resistant rats. Int J Obes (Lond) 2010;34:1218-1226.

48 Cavagnini F, Croci M, Putignano P, Petroni ML, Invitti C: Glucocorticoids and neuroendocrine function. Int J Obes Relat Metab Disord 2000;24:S77-79.

49 Hou M, Liu Y, Zhu L, Sun B, Guo M, Buren J, Li X: Neonatal overfeeding induced by small litter rearing causes altered glucocorticoid metabolism in rats. PLoS One 2011;6:e25726.

50 de Jesus LA, Carvalho SD, Ribeiro MO, Schneider M, Kim SW, Harney JW, Larsen PR, Bianco AC: The type 2 iodothyronine deiodinase is essential for adaptive thermogenesis in brown adipose tissue. J Clin Invest 2001;108:1379-1385.

-51 Araujo RL, Andrade BM, da Silva ML, Ferreira AC, Carvalho DP: Tissue-specific deiodinase regulation during food restriction and low replacement dose of leptin in rats. Am J Physiol Endocrinol Metab 2009;296:E1157-1163.

52 Toyoda N, Yasuzawa-Amano S, Nomura E, Yamauchi A, Nishimura K, Ukita C, Morimoto S, Kosaki A, Iwasaka T, Harney JW, Larsen PR, Nishikawa M: Thyroid hormone activation in vascular smooth muscle cells is negatively regulated by glucocorticoid. Thyroid 2009;19:755-763.

53 Smorlesi A, Frontini A, Giordano A, Cinti S: The adipose organ: White-brown adipocyte plasticity and metabolic inflammation. Obes Rev 2012;13:83-96.

-54 Bostrom P, Wu J, Jedrychowski MP, Korde A, Ye L, Lo JC, Rasbach KA, Bostrom EA, Choi JH, Long JZ, Kajimura S, Zingaretti MC, Vind BF, Tu H, Cinti S, Hojlund K, Gygi SP, Spiegelman BM: A pgc1-alpha-dependent myokine that drives brown-fat-like development of white fat and thermogenesis. Nature 2012;481:463468.

55 Cinti S: Transdifferentiation properties of adipocytes in the adipose organ. Am J Physiol Endocrinol Metab 2009;297:E977-986.

-56 Bachman ES, Dhillon H, Zhang CY, Cinti S, Bianco AC, Kobilka BK, Lowell BB: Betaar signaling required for diet-induced thermogenesis and obesity resistance. Science 2002;297:843-845.

57 Cinti S: Adipocyte differentiation and transdifferentiation: Plasticity of the adipose organ. J Endocrinol Invest 2002;25:823-835.

58 Cinti S: The role of brown adipose tissue in human obesity. Nutr Metab Cardiovasc Dis 2006;16:569-574.

59 Ravussin E, Galgani JE: The implication of brown adipose tissue for humans. Annu Rev Nutr 2011;31:33-47.

60 Blessing W, Mohammed M, Ootsuka Y: Brown adipose tissue thermogenesis, the basic rest-activity cycle, meal initiation, and bodily homeostasis in rats. Physiol Behav 2013;121:61-9.

61 Kontos A, de Menezes RC, Ootsuka Y, Blessing W: Brown adipose tissue thermogenesis precedes food intake in genetically obese zucker (fa/fa) rats. Physiol Behav 2013;118:129-137. 